\title{
MELAMPAUI SINOLOGI TRADISIONAL
}

\author{
Natalia Soebagjo
}

\begin{abstract}
Abstrak
Kepulauan Nusantara sudah lama menjalin hubungan dengan Cina. Sejarah panjang ini tentu mengalami masa pasang surut, terutama di zaman modern saat hubungan kedua negara dipengaruhi oleh perkembangan politik dalam negeri. Dengan bangkitnya Cina pada abad ke-21, menjadi semakin penting untuk bisa memahami dan mengantisipasi langkah-langkah kebijakan yang diambil Cina berkaitan dengan dampaknya pada bangsa Indonesia. Untuk itu, diperlukan ahli-ahli Cina yang tidak saja menguasai bahasa dan budaya Cina tetapi juga mempunyai keahlian ilmu disiplin lain agar dapat lebih tajam menganalisa perkembangan Cina modern. Ilmu sinologi dalam pengertian tradisional terbatas pada penguasaan bahasa dan budaya - tidak lagi cukup untuk menghadapi Cina yang semakin berperan di kancah dunia.
\end{abstract}

Kata Kunci

\begin{abstract}
Indonesia has had a long history of interaction with China marked with periods of warm understanding and cold misunderstandings. In the modern era in particular ties have been complicated by domestic politics. As China rises in the 21st century and takes its place in the world, Indonesia has to be able to define its relationship vis-a-vis China. To be able to do this, Indonesians need to better understand China. Ability to understand the Chinese language and China's culture, although basic and essential, is no longer enough. The study of modern China needs to go beyond the traditional understanding of Sinology, strengthened by other academic disciplines, if Indonesians want to better anticipate the dynamics of Indonesia-China relations.
\end{abstract}

Keywords

\section{PENGANTAR}

Interaksi masyarakat kepulauan Nusantara dengan orang Cina sudah lama berlangsung, bahkan menurut kitab-kitab kuno Cina sejarah hubungan kerajaankerajaan di Nusantara dan Cina sudah terjalin sejak dinasti Han, 2000 tahun yang lalu. Sejarah yang demikian lama tentu mengalami pasang surut yang sesungguhnya dapat dihindari apabila kedua bangsa saling mengenal dan memahami bahasa, adat-istiadat, sejarah, pemikiran dan worldview masing-masing. 
Akan tetapi, meskipun kita sudah lama berhubungan dengan Cina, hidup bersama dengan masyarakat keturunan etnis Tionghoa di Tanah Air, pemahaman kita tentang Cina dan orang Cina terbatas dan terbentuk oleh keadaan politik dalam negeri kita, terutama sejak zaman kolonial Hindia Belanda hingga masa pasca-Kemerdekaan. Ilmu sinologi bermaksud untuk mengatasinya dengan membuka tabir ketidak-tahuan kita.

Bangsa Cina sekarang sudah bukan lagi Cina yang tertindas oleh kekuatan kolonial abad ke-19, bukan lagi negara yang tertutup seperti pada zaman radikalisme Mao. Abad ke-21 adalah abad Asia-Pasifik dan Cina berada di tengah-tengahnya. Cina sekarang telah bangkit kembali, mengingatkan kita pada masa kejayaannya zaman Tang (618-906 M) saat Cina kuat bersatu, makmur, dengan budaya yang tinggi. Di bawah kendali Kaisar Xuangzong pada abad ke-8, Cina merupakan kekuatan ekonomi dan politik terkuat di dunia. History repeats itself dan oleh karenanya kita wajib belajar darinya untuk yakin menghadapi masa depan. Tantangannya adalah bagaimana mengantisipasi suatu masa depan dengan Cina kembali jaya.

\section{CINA KINI}

Ahli ekonomi Cina, Elizabeth Economy, menegaskan apa yang sudah kita ketahui, yaitu bahwa RRC telah menjadi kekuatan ekonomi besar yang tentunya akan mempengaruhi kebijakan luar negerinya. Bagaimana tidak, buktinya, menurut Economy, adalah:

"Beijing has pushed to the forefront of the emerging economies, negotiated wide-ranging free-trade
agreementes with its neighbors, and rejuvenated previously moribund economies through its demand
for natural resources. Its vast foreign currency holdings have also transformed Beijing into the
world's banker. China is now the largest foreign holder of U. S. debt. It is a more significant provider
of loans to the developing world than the world Bank, and is one of the few global economies capable
of significant assistance in the midst of the eurozone crisis." 1

Tak lupa pula bahwa Cina adalah anggota tetap Dewan Keamanan PBB. Di G20 dan di G77 Cina juga berperan, bahkan pernah ada wacana mengenai G2 dimana hanya Cina dan Amerika yang berarti dalam perekonomian dunia.

Prestasi dalam negeri Cina tidak kalah menakjubkan. Menurut Human Development Index yang disusun oleh UNDP, pada tahun 2011 tingkat kesejahteraan rakyat Cina dari aspek kesehatan, pendidikan dan pendapatan menduduki peringkat ke-101 dari 187 negara yang dipantau, dengan nilai 0.687, melebihi rata-rata untuk wilayah Asia Timur dan Pasifika (0.671). Bandingkan dengan dengan nilai 0.617 dan peringkat 124 untuk Indonesia. $^{2}$ Dalam kurun waktu 25 tahun, Cina berhasil mengentaskan 600 juta jiwa dari

\footnotetext{
1 Economy, Elizabeth. “Time for a Strategic Reset". America's Quarterly Winter 2012

2 UNDP, Human Development Report 2011
} 
kemiskinan. Pada tahun 1981, 85\% dari penduduknya hidup dengan hanya US\$1.25 per hari. Pada tahun 2004, angka tersebut turun menjadi 27\%. Yang berkonsumsi kurang dari US\$1 per hari juga turun dari $65 \%$ menjadi $10 \% .^{3}$

Sementara waktu, walaupun sulit mengartikan kelas menengah dalam konteks Cina, jumlah mereka meningkat. Kaum sosiolog RRC menggunakan empat kriteria yang lazim digunakan untuk menentukan siapa yang tergolong kelas menengah, yaitu pendapatan, pekerjaan, pendidikan, dan pola konsumsi, ditambah dengan pengelompokkan berdasarkan empat kelompok sosial berbeda, yaitu para wiraswasta besar (kelas kapitalis); kaum profesional, manajer dan pejabat (kelas menengah baru); pengusaha kecil (kelas menengah lama) dan terakhir pegawai rendahan (kelas menengah marginal). Pada tahun 2006, diperkirakan bahwa 64\% dari penduduk kota merupakan kelas menengah secara keseleruhan. Akan tetapi kalau dibatasi pada kelas kapitalis dan kelas menengah baru saja, jumlah mereka hanya 18\% dari penduduk kota dan $9 \%$ dari jumlah penduduk atau 118,3 juta jiwa. ${ }^{4}$

Media akhir-akhir ini menyitir Helen Wang, seorang konsultan yang dibesarkan di China kemudian hijrah ke Amerika Serikat. Menurutnya, rumah tangga Cina yang terdiri dari tiga orang, dengan pendapatan per tahun antara US\$10.000-US\$60.000 dan memiliki discretionary spending sekitar 30\%, tergolong kelas menengah. Jumlah mereka sekitar 300 juta-lebih besar daripada jumlah penduduk Amerika-dan diperkirakan akan mencapai 700-800 juta pada tahun 2020.5 Dalam kurun waktu satu generasi, UN Population Division dan Goldman Sachs memperkirakan bahwa jumlah kelas menengah di Cina akan 4 kali lebih besar daripada kelas menengah di Amerika yaitu 1,4 milyar konsumen kelas menengah, suatu pasar yang sangat menggiurkan. ${ }^{6}$ Selain akan berdampak secara ekonomis, suara kelas baru ini juga akan meramaikan kehidupan politik bangsa Cina.

Tidak berarti bahwa pertumbuhan ekonomi Cina yang demikian pesat tidak bermasalah. Dalam negeri Cina menghadapi berbagai persoalan-persoalan pelik. Ketimpangan sosial yang semakin besar, korupsi, perubahan demografik, kerusakan lingkungan hidup, tuntutan masyarakat yang semakin vokal dan keberlanjutan pertumbuhan hanya sebagian dari daftar yang panjang. Di panggung dunia, Cina juga menghadapi tuntutan agar Cina menjadi warga komunitas internasional yang lebih bertanggung-jawab, misalnya dalam penanganan perubahan iklim, krisis ekonomi

\footnotetext{
3 World Bank. From poor areas to poor people: China's evolving povery reduction agenda. March 2009

4 Li Chunling. "Characterizing China's Middle Class: Heterogenous Composition and Multiple Identies" dalam Cheng Li, ed. China's Emerging Middle Class: Beyond Economic Transformation. (Washington DC: Brookings Institution Press. 2010)

${ }^{5}$ Luhby, Tami. “China's growing middle class”. CNN Money. 26 April 2012 diunduh 29 Juli 2012.

6 Rapoza, Kenneth. "Within a generation, China middle class four times larger than America's" Forbes. 9 Mei 2011 diunduh 29 Juli 2012
} 
dunia, dan akhir-akhir ini kemelut di Timur Tengah.

Kekhawatirannya adalah mengenai apa yang hendak Cina lakukan dengan kekuatan ekonominya, terutama di kawasan kita? Apakah Cina akan membanjiri kita dengan produk-produk murahnya, sambil menguras sumber alam kita? Ataukah Cina akan menjadi kekuatan militer, mengancam negara-negara tetangganya? Keraguan seperti ini menentukan sikap berhati-hati hedging kita sambil tetap engage Cina, baik secara bilateral maupun regional.

Keteguhan sikapnya mengenai Laut Cina Selatan, misalnya, merupakan suatu ancaman yang riil bagi Filipina. Penyelesaian lewat ASEAN semakin sulit, apalagi dengan Kambodia sebagai ketua ASEAN. Di balik kegagalan AMM untuk mengeluarkan joint communique - yang tak pernah terjadi dalam sejarah ASEAN adalah faktor Cina yang memecah-belahkan ASEAN. Kambodia, selaku ketua ASEAN dengan hubungan bilateral yang dekat dengan Cina, tidak ingin mengangkat masalah Cina dan masalah Laut Cina Selatan dalam communique tersebut, sedangkan Filipina dan Vietnam keberatan. Untuk menghadapi Cina dan menyelesaikan kemelut tersebut, penyelesaian bilateral tidak cukup dan memerlukan sikap ASEAN yang jelas. Demi menjaga kredibilitas ASEAN, Indonesia turun tangan untuk meredakan ketegangan intern ASEAN. Dalam waktu 36 jam, Menlu RI Marty Natalegawa berhasil mencapai kesepakatan antar anggota ASEAN mengenai Laut Cina Selatan yang dituangkan dalam "ASEAN Common Position on the South China Sea". Salah satu prinsip yang disepakati adalah agar suatu code of conduct dirumuskan bersama secepatnya untuk menangani Laut Cina Selatan dan, nampaknya, Cina tidak keberatan dengan gagasan tersebut. ${ }^{7}$

Walaupun sering dipertanyakan sejauh manakah Cina sesungguhnya bisa mempengaruhi negara-negara di ASEAN dan pilihan-pilihan strategis mereka, peristiwa tersebut menunjukkan Cina tetap dapat menggangu solidaritas ASEAN. ${ }^{8}$

\section{HUBUNGAN RI-RRC}

Bagaimana posisi Indonesia di tatanan baru ini? Apakah Indonesia bisa menghadapi Cina sebagai mitra setara? Sebagai sesama anggota G-20, negara demokrasi terbesar ketiga di dunia, perekonomian terbesar di ASEAN,wajar apabila Indonesia mempunyai keinginan untuk menjadi suara yang didengar di tatanan dunia, paling tidak di panggung regional. Kedua negara ini saling memerlukan. Cina melihat Indonesia sebagai aktor penting di kawasan Asia Timur sedangkan Indonesia memerlukan Cina untuk mendukung kebangkitanya di panggung internasional.

Hubungan Indonesia-Cina sejak kemerdekaan kedua negara penuh gejolak,

\footnotetext{
7 Sukma, Rizal. "After regaining unity, it is time to move forward." The Jakarta Post. 27 Juli 2012

8 Goh, Evelyn. "Rising Power...to do what?: Evaluating China's Power in Southeast Asia". RSIS Working Paper no.226. 30 March 2011
} 
dipengaruhi oleh warisan sejarah yang terhimpun sejak gelombang pertama kedatangan orang Cina di Nusantara pada abad ke-13; status kelompok etnis Tionghoa; perang melawan komunisme pada era Perang Dingin; persepsi diri Indonesia sebagai primus inter pares di Asia Tenggara, dan pertimbangan pragmatis ekonomi yang kini mendominasi. ${ }^{9}$ Menurut Jusuf Wanandi, persepsi ancaman Cina juga diterbentuk oleh bahaya subversi, besarnya Cina dan keberadaannya di suatu kawasan dimana secara historis, Cina telah berusaha menunjukkan kedaulatannya. ${ }^{10}$

Pada tahun 1980, penjajagan untuk mencairkan hubungan antar kedua negara dimulai oleh kementerian luar negeri kedua negara akan tetapi pada saat itu masih sulit menghadapi resistensi Soeharto dan ABRI. Baru lima tahun kemudian, setelah Soeharto merasa yakin bahwa Cina tidak akan campur tangan dalam masalah domestik Indonesia, hubungan dagang antar kedua negara pertama-tama dibuka untuk kemudian berkembang menuju normalisasi hubungan diplomatis pada tahun 1990.

Pada tahun-tahun awal hubungan diplomatis, Indonesia masih sangat berhatihati, terutama setelah peristiwa kerusuhan buruh di Medan pada tahun 1994 yang kemudian berkembang menjadi kerusuhan anti-Cina. Kementerian Luar Negeri RRC mengeluarkan pernyataan kepedulian dan himbauan agar kerusuhan segera diatasi yang dianggap oleh Jakarta sebagai sikap campur tangan Cina dalam masalah intern Indonesia. Oleh karena itu, ketika jatuhnya Soeharto pada bulan Mei 1998 diwarnai oleh kerusuhan-kerusahan dimana banyak korban adalah orang Tionghoa, Cina menahan diri dan tidak langsung memberi reaksi. Dalam bulan-bulan menjelang Mei 1998, ketika Indonesia menghadapi krisis keuangan, Cina juga cerdas dalam menentukan sikap. Indonesia sangat terpukul, menyaksikan nilai mata uang rupiah anjlok dari rata-rata Rp.2,342 pada tahun 1996, menjadi Rp.10.014 dua tahun kemudian. Melihat dampak dari krisis keuangan Asia pada negara-negara tetangganya, Cina memutuskan untuk tidak melakukan devaluasi mata uangnya untuk menghindari penurunan yang lebih tajam mata uang negara-negara di kawasan. Langkah ini meningkatkan citra Cina di Asia, termasuk di Indonesia.

Baru setelah Soeharto jatuh pada tahun 1998, hubungan kedua negara berkembang pesat. Bagi Abdurrahman Wahid, presiden pertama yang dipilih secara demokratis pada bulan Oktober 1999 dan terkenal dengan gaya kepemimpinannya yang amat informal, 'masalah Cina' tidak lagi dijadikan masalah, baik dari yang berkaitan dengan etnis Tionghoa di dalam negeri, maupun dengan RRC di luar negeri. Di dalam negeri, Gus Dur mencabut Inpres 14/1967 dan memberi kembali hak-hak budaya dan kepercayaan orang Tionghoa di Tanah Air serta memberi pengakuan atas peran dan sumbangsih

\footnotetext{
9 Storey, Ian. "Progress and Remaining Obstacles in Sino-Indonesian Relations." China Brief Vol.5 No.18. Jamestown Foundation

${ }^{10}$ Wanandi, Jusuf. Shades of Grey: A political memoir of Modern Indonesia 1965-1998. (Jakarta: Equinox. 2012)
} 
mereka dalam kehidupan berbangsa kita. Sedangkan Cina adalah negeri pertama yang dikunjunginya secara resmi karena Gus Dur menyadari potensi Cina bagi pemulihan ekonomi kita. Megawati dan SBY kemudian melanjutkan kebijakan bersahabat dengan RRC yang digiatkan oleh Abdurrahman Wahid, memuncak dengan ditanda-tanganinya perjanjian kemitraan strategis pada tahun 2005 yang sangat komprehensif, mencakup kerjasama di bidang politik, pertahanan, keamanan, hukum, ekonomi dan sosial-budaya.

Sekarang, pertimbangan ekonomi adalah perekat terkuat hubungan kedua negara besar di Asia ini. Menurut seorang ekonom Cina, Wu Chongbo, ada beberapa alasan mengapa hubungan ekonomi kedua negara ini begitu cepat berkembang. Pertama, devisa Cina sudah mencapai US $\$ 1,9$ trilyun dan pemerintah Cina mendorong persuahaan-perusahaannya untuk 'go international', berinvestasi di ASEAN; kedua, Cina memerlukan sumber energi, bahan baku dan komoditas baru di luar Cina yang aman dan stabil yang dimiliki Indonesia; ketiga, Indonesia sebagai negara dan perekonomian terbesar di Asia Tenggara menjadi incaran kekuatan-kekuatan besar seperti Cina, Jepang dan Amerika Serikat dan Cina tidak ingin ketinggalan; keempat, Indonesia menyambut investasi dari Cina, terutama di bidang manufaktur, tidak lagi terbatas pada bidang sumber daya alam dan infrastruktur. Selain itu, dengan adanya CAFTA, peluang dagang dan investasi semakin besar. ${ }^{11}$

Pada bulan Maret 2012, Presiden Susilo Bambang Yudhoyono mengunjungi Cina dan menyaksikan penanda-tanganan 15 perjanjian bisnis bernilai US\$17.65 milyar dan $5 \mathrm{MoU}$ mengenai kerjasama maritim, anti-narkoba, pertukaran data statistik dan arsip. Target volume perdagangan bilateral untuk 2015 ditentukan pada US\$ 80 milyar yang akan mudah tercapai apabila menggunakan statistik Cina yang sudah mencatat US\$60 milyar, berbeda dengan pencatatan Indonesia sebesar US\$49.15 milyar. SBY ke RRC juga untuk mencari dukungan untuk 2011-2015 Master Plan for Acceleration and Expansion of Indonesia's Economic Development (MP3EI). Pada tingkat regional, Indonesia mengharapkan Cina akan lebih aktif di ASEAN +1, +3 dan di East Asia Summit.

Di kemudian hari, hubungan kedua negara akan menjadi semakin kompleks, tidak sekadar untuk kepentingan pragmatis ekonomi tetapi juga untuk kepentingan politikkeamanan di kawasan. Menurut Rizal Sukma, ada tiga hal yang dapat mempengaruhi hubungan bilateral kita. Di antaranya, tetap persepsi publik tentang kaum etnis Tionghoa, walau akan semakin kecil pengaruhnya. Kedua adalah kepercayaan publik terhadap Cina dan ambisinya di kawasan. Ketiga adalah bagaimana Cina mengatasi perselisihan yang timbul dalam hubungan bilateral. ${ }^{12}$ Akan tetapi, untuk membangun

\footnotetext{
${ }^{11}$ Wu Chongbo. "Forging Closer Sino-Indonesian Economic Relations and Policy Suggestions." Ritsumeikan International Affairs Vo.10. 2011 pp 119-142

12 Sukma, Rizal. "Indonesia's Response to the Rise of China: Growing Comfort amid Uncertainties" dalam Rise of China: Responses from Southeast Asia and Japan. NIDS Joint Research Series no.4, 2009
} 
hubungan bilateral berdasarkan prinsip-prinsip saling menghormati, memerlukan pemahaman tentang dinamika politik dan sosial-ekonomi dalam negeri Cina yang akan mewarnai kebijakan luar negeri Cina.

Disinilah kelemahan kita. Apabila Indonesia berambisi untuk berperan lebih besar dalam percaturan ekonomi, politik dan strategis regional, kita harus berhadapan dengan Cina. Apakah pengetahuan dan pemahaman kita tentang negara raksasa tersebut memadai?

\section{SINOLOGI DI INDONESIA}

Orang Indonesia pertama yang merintis ilmu pengetahuan tentang Cina, khususnya bahasa dan kebudayaan Cina sebagai suatu academic discipline, adalah oleh Prof Dr TjanTjoe Som (1903-1969), sinolog lulusan Universitas Leiden. Tjan Tjoe Som, bersama adiknya, Tjan Tjoe Siem, berasal dari keluarga peranakan Muslim dari Surakarta yang masing-masing meraih prestasi akademik yang tinggi. Tjan Tjoe Siem seorang lulusan dari Universitas Leiden dengan gelar PhD dalam ilmu Javanologi pada tahun 1938 sedangkan Tjan Tjoe Som menyusul lulus sebagai Sinolog pada tahun 1949. Tidak mengherankan karena keduanya dibesarkan dalam lingkungan keluarga peranakan yang kental dengan pengaruh dua budaya, yaitu budaya Jawa dan Cina. Salah satu leluhur mereka bahkan berjasa dalam Perang Diponegoro (1825-1830) dan dianugerahkan penghargaan oleh Mangkunegara III. ${ }^{13}$ Akan tetapi, nasib kedua bersaudara tersebut berbeda.

Pada tahun 1958, Tjan Tjoe Som menjadi anggota Himpunan Sardjana Indonesia dan juga seorang direktur Universitas Rakyat yang berafiliasi dengan PKI. Karena itu, 10 tahun kemudian, Tjan Tjoe Som, seorang guru besar, ahli filsafat Cina dan hukum Islam, diberhentikan tidak dengan hormat, tanpa hak pensiun, dari Universitas Indonesia oleh Mendikbud. Dasar pemecatatannya adalah bahwa Tjan Tjoe Som dianggap patut diduga terlibat dalam "G30S" secara langsung atau tidak langsung, menjadi anggota biasa dari suatu organisasi terlarang di bawah PKI, dan sebagai pegawai negeri dianggap telah melakukan perbuatan yang bertentangan dengan kepentingan dinas dan negara. Setelah mengembangkan ilmu Sinologi di Indonesia sejak tahun 1952, karir “Bapak Sinologi” Prof Dr Tjan Tjoe Som berakhir begitu saja pada usia 64 tahun., menjadi korban politik masa itu. Setahun kemudian, Prof Dr Tjan Tjoe Som meninggal di Bandung enam minggu sebelum ulang tahunnya ke-66 dan jenazahnya dimakamkan di Surakarta, kota kelahirannya. ${ }^{14}$

\footnotetext{
${ }_{13}$ Suryadinata, Leo. Eminent Indonesian Chinese: Biographical Sketches. (Singapore: Gunung Agung, 1981)

${ }^{14}$ Agni Malagina. “Tjan Tjoe Som 1903-1969: Sepenggal Kisah Sunyi di Sinological Insitute, Fakultet Sastra Universitet Indonesia" diunduh dari blog amalgina.multiply.com/journal/item/108/108 pada 25 Agustus 2012.
} 
Pada awalnya, Tjan Tjoe Som mempelajari sinologi, islamologi, filsafat dan antropologi secara otodidak. Minatnya mencerminkan lingkungan dimana ia dibesarkan. Setelah lulus dari pendidikan Algemene Middelbare School AMS) di Yogyakarta, Tjan Tjoe Som kembali ke Surakarta untuk menjalankan usaha keluarganya. Perkenalannya dengan Prof. Duyvendak yang kemudian mendorongnya untuk berangkat ke Negeri Belanda untuk kuliah di Universitas Leiden pada tahun 1936.

Kala itu, pusat dari sinologi sebagai academic discipline di Eropa sebetulnya tidak di Universitas Leiden, melainkan di Perancis, di College de France yang pada tahun 1814 mendirikan suatu "chaire de langues et littéeratures chinoises et tartares-mandchoues". Keunggulan "Paris School" terus bertahan sampai Perang Dunia ke-II. ${ }^{15}$ Sinologi di Leiden dikembangkan oleh J.J.M de Groot dan G. Schlegel baru pada akhir abad ke19, terkait dengan kebutuhan akan penterjemah bahasa Cina di Hindia Belanda akibat bertambahnya buruh Cina dan keresahan-keresahan sosial politik yang terjadi, disebabkan oleh kebijakan divide et impera penguasa kolonial.

Pada tahun 1855, pemerintah Hindia Belanda mengutus dua orang Belanda ke Cina untuk belajar, disusul dengan 2 orang lagi pada tahun 1857. Akhirnya terkumpul lima orang, diantaranya G. Schlegel, dan mereka adalah sinolog angkatan pertama yang kemudian mendirikan kantor penterjemah pada tahun $1860 .{ }^{16}$ Dalam perkembangannya, tugas kantor-kantor tersebut diperluas menjadi "Kantoor voor Chineesche Zaken" (Kantor Masalah-masalah Cina) untuk memperdalam pengenalan dan pengetahuan pemerintah kolonial tentang kehidupan masyarakat Cina di Hindia Belanda. Cabang-cabang kantor penterjemah dapat ditemukan di Batavia, Surabaya, Tanjung Pinang, Medan, dan Makassar. ${ }^{17}$

Sedangkan J.J.M de Groot adalah dosen bahasa Mandarin Prof. Duyvendak. Setelah bertugas di Kedutaan Belanda di Beijing sebagai penterjemah pada tahun 19121918, Duyvendak kembali ke Leiden untuk mengajar dan pada tahun1930 Duyvendak diangkat sebagai professor, kemudian mendirikan Sinological Institute. Berbeda dengan sinolog Belanda lain, Duyvendak tidak pernah memangku jabatan di Hindia Belanda. ${ }^{18}$

Untuk belajar bahasa Cina, kaum Tionghoa Peranakan di Hindia Belanda memiliki sekolah-sekolah mereka sendiri. Mereka yang mampu mendatangkan tutor dari Cina Daratan untuk memberi les privat anak-anak mereka. Pada tahun 1729, sekolah Cina tradisional pertama didirikan dengan menggunakan dialek Hokkian.

\footnotetext{
${ }^{15}$ Brodsgaard, Kjeld Erik. "China Studies in Europe” dalam Shambaugh, Sandschneider, Zhou eds. ChinaEurope Relations: Perceptions, policies and prospects. (New York: Routledge, 2008)

16 Selain G. Schlegel ada J.E. Albrecht, G. von Faber, J.J.C. Francken dan W.P. Groeneveldt. Lohanda, Mona. Growing Pains: The Chinese and the Dutch in Colonial Java, 1890-1942 (Jakarta: Yayasan Cipta Loka. 2002)

17 Ibid.

${ }_{18}$ Diunduh dari www.umass.edu/wsp/sinology/persons/duyvendak.html 25 Agustus 2012
} 
Karena tidak dikelola dengan baik, akhirnya sekolah tersebut tidak bertahan lama dan baru berkembang kembali pada akhir abad ke-19. Yang dipelajari dan dihafal muridmurid sekolah tersebut adalah kitab-kitab klasik Cina sehingga para lulusan tetap tidak dapat bertutur kata dalam bahasa Cina dengan baik. Baru pada 1901, sekolah dasar Cina yang modern didirikan di Batavia dengan bahasa guoyu sebagai bahasa pengantar. Sekolah-sekolah serupa berkembang dan banyak di antara mereka dikelola oleh kelompok-kelompok dialek tertentu, seperti kelompok bahasa Kanton dan Hakka.

Khawatir akan popularitas sekolah-sekolah tersebut dan akan terjadinya peralihan loyalitas ke Cina Daratan, sebagai tandingan, penguasa kolonial mulai mendirikan sekolah-sekolah Belanda-Cina yang berorientasi ke Belanda pada tahun 1908. Mengingat bahwa lulusan sekolah Belanda-Cina akan lebih mudah mendapatkan pekerjaan dalam birokrasi kolonial dan peluang lulusannya untuk masuk perguruan tinggi akan lebih besar, sekolah-sekolah tersebut menjadi lebih menarik. ${ }^{19}$ Meskipun demikian, sekolahsekolah Cina tetap bertahan hingga kebijakan Orde Baru melarangnya pada tahun 1967.

Pengajaran bahasa Cina pada tingkat universitas baru dimungkinkan saat departemen sinologi dibuka di Fakultas Sastra dan Filsafat pada tahun 1947. Meskipun Tjan Tjoe Som memiliki karir yang baik sebagai pustakawan Sinological Insititute, kemudian sebagai Chair of Chinese Philosophy di Leiden, dan meskipun dibujuk oleh kolega-koleganya untuk tetap di Negeri Belanda, Tjan Tjoe Som memutuskan untuk kembali ke Tanah Air pada tahun 1952 untuk memenuhi undangan pemerintah Republik Indonesia menjadi ketua Lembaga Sinologi di Universitas Indonesia.

Meskipun pengertian tradisional sinologi adalah fokus pada penguasaan bahasa dan pengenalan budaya, Tjan Tjoe Som mengembangkan Lembaga Sinologi dengan pendekatan multi-disipliner. Dengan penuh dedikasi Tjan Tjoe Som mengajar, mengembangkan kurikulum dan membangun perpustakaan Lembaga Sinologi. Selain mendidik sinolog-sinolog, Lembaga Sinologi juga menawarkan kursus-kursus sinologi praktis untuk pegawai negeri dari berbagai instansi. Akan tetapi Tjan Tjoe Som juga memperkenalkan mata kuliah Cina kontemporer, menggunakan putonghua dan mengirim dosen untuk pelatihan di Cina agar saat mereka kembali akan lebih mampu mengajar bahasa Cina modern, menggunakan pinyin. ${ }^{20}$ Pengembangan sinologi berakhir dengan meletusnya G30S tahun 1965 dan putusnya hubungan diplomatik dengan RRC pada tahun 1967.

Selain melalui interaksi masyarakat dengan kelompok etnis Tionghoa, persepsi dan pengetahuan kita tentang Cina selama ini dipengaruhi oleh sekelompok kecil

${ }_{19}$ Gondomono. "The Development of the Teaching of Chinese Language in Indonesia" Jurnal Ilmiah Darma Persada. Tahun III/3/Juli 2005

${ }^{20}$ A. Dahana. "Chinese Studies in Indonesia: Opportunities for Cooperation". Makalah yang disampaikan dalam ASEAN Universitis Network-Chinese Universities Roundtable Discussion di Beijing, Cina, Mei 2004. 
masyarakat kita, yaitu segelintir sinolog, elit politik dan budaya. ${ }^{21}$ Setelah pembekuan hubungan diplomatik, pengetahuan tentang RRC dimonopoli oleh ABRI dan para Cold War warriors dengan perspektif keamanan dan ancaman yang dominan. TAP MPRS XXXII/1966 melarang penggunaan bahasa Cina dan aksara Cina dan Instruksi Presiden No.14 tahun 1967 melarang pelaksanaan adat-istiadat budaya dan agama Cina di hadapan publik. Kelompok etnis Tionghoa diarahkan melalui peraturan pemerintah untuk membaur dengan masyarakat pribumi. Dalam suasana yang demikian menghimpit, Jurusan Sastra Cina tetap berjalan walaupun minat terhadap sinologi menurun drastis. Sebagian besar staf pengajar dituduh sebagai simpatisan PKI dan dihentikan, termasuk Prof Dr Tjan Tjoe Som, dan tidak ada yang berani untuk mendaftar karena khawatir akan dituduh pro-komunisme.

Situasi mereda baru pada tahun 1973 dan ada penerimaan mahasiswa baru, walau hanya enam orang. Lembaga Sinologi telah dilebur dalam Fakultas Sastra UI, menjadi Jurusan Sastra Cina yang kemudian berubah nama lagi menjadi Program Studi Cina, bagian dari Fakultas Ilmu Budaya UI. Mengingat bahwa ada larangan impor barang dari RRC, buku pelajaran yang digunakan berasal dari Amerika Serikat dan itupun hanya bisa diimpor dengan izin khusus pihak keamanan.

Genggaman pihak ABRI dan keamanan melunak ketika hubungan dagang dibuka pada tahun 1985 dan para pejabat dan pengusaha diberi akses terbatas untuk mengunjungi Cina Daratan. Universitas Darma Persada membuka jurusan sastra Cina, menjadi universitas swasta pertama yang melakukannya, mendobrak monopoli pengajaran sastra Cina yang dikuasai oleh UI selama 40 tahun lebih.

Setelah hubungan diplomatik dicairkan pada tahun 1990, minat masyarakat untuk menguasai bahasa Mandarin melonjak. Universitas Indonesia dan Universitas Darma Persada membuka kursus bahasa Mandarin untuk umum dan kedua universitas tersebut menjadi rujukan bagi lembaga-lembaga pendidikan lain yang ingin menyelenggarakan kelas bahasa Mandarin. Setelah Presiden Abdurrahman Wahid membatalkan Instruksi Presiden No.14 tahun 1967 dengan Keputusan Presiden No. 6 Tahun 2000, animo tak terbendung lagi. Perjanjian kerjasama dalam bidang pendidikan bahasa Mandarin nonformal ditanda-tangani antar Cina-Indonesia dan pada tahun 2001, Konsorsium Kursus Bahasa Mandarin dibentuk untuk menjaga mutu pendidikan mengingat menjamurnya lembaga-lembaga yang menawarkan kursus bahasa Mandarin.

Pada tingkat universitas, berbagai universitas telah mendirikan Confucius Institutes atau Pusat Bahasa Mandarin, yaitu Universitas Al-Azhar (Jakarta), Universitas Negeri Surabaya, Universitas Hasanuddin, Universitas Negeri Malang, Universitas

\footnotetext{
${ }^{21}$ Untuk kajian menarik mengenai pembentukan persepsi elit politik dan budaya Indonesia dan bagaimana persepsi tersebut menjadi suatu metafora untuk menghadapi transformasi masyarakat pascakolonialisme baca Hong Liu, China and the Shaping of Indonesia 1949-1965. Kyoto CSEAS Series on Asian Studies 4. (Kyoto: Center for S.E. Asian Studies Kyoto University. 2011).
} 
Tanjungpura, Universitas Kristen Maranatha, dan di Bina Terampil Insan Persada, suatu lembaga kursus bahasa Mandarin yang mendirikan Institut Kongzi pertama pada tahun 2007. Pusat-pusat bahasa tersebut didukung oleh Hanban, badan di bawah Kementerian Pendidikan RRC, dengan mandat khusus untuk mendorong pengajaran bahasa Mandarin di seluruh dunia. Pada bulan Juni 2012, angkatan pertama guru SMA bahasa Mandarin dikirim ke Cina sebanyak 30 orang untuk dilatih selama 6 bulan di Fujian Normal University. ${ }^{22}$

Minat belajar di RRC juga meningkat. Setiap tahun sejak 2003, pemerintah Cina menggelar pameran pendidikan di Jakarta dan kota-kota besar lain. Pada pameran tahun 2012, 23 perguruan tinggi Cina berpartisipasi dan pameran dikunjungi oleh 40,000 orang. ${ }^{23}$ Setiap tahun, jumlah pelajar dan mahasiswa yang menuntut ilmu di RRC meningkat 15\% dan kini jumlah mereka diperkirakan sudah mencapai hampir 11,000 siswa. ${ }^{24}$

Perkembangan ini tentu merupakan perkembangan yang positif. Pengenalan bahasa dan budaya merupakan langkah pertama untuk memahami bangsa lain. Akan tetapi, miat untuk belajar bahasa Mandarin dan untuk mengenal budaya orang Cina masih pada berlandaskan pertimbangan pragmatis, yaitu didorong oleh keinginan untuk memanfaatkan peluang-peluang bisnis dan ekonomi yang ditawarkan oleh pertumbuhan ekonomi Cina yang pesat. Animo tersebut juga merupakan reaksi balik atas kebijakan stigmatisasi, marjinalisasi dan viktimisasi Orde Baru terhadap kelompok etnis Tionghoa yang hak-hak kewarganegaraan dan budaya mereka kini telah diberikan kembali. $^{25}$ Di era, pasca-Gus Dur, masyarakat etnis Tionghoa diberi ruang untuk mempertanyakan identitas mereka sebagai seorang keturunan Cina yang lahir dan dibesarkan di Indonesia dan salah satu upaya mencari jawabannya adalah melalui penguasaan bahasa Mandarin.

\section{MELAMPAUI SINOLOGITRADISIONAL}

Kini tidak ada batasan lagi dalam hubungan kita dengan RRC. Pertukaran antar bangsa menjadi semakin longgar, melibatkan pelaku negara dan non-negara. Tidak ada lagi Tirai Bambu, Cina sudah terbuka terhadap dunia luar sedangkan di Indonesia, alam demokratisnya tidak memungkinkan adanya memonopoli informasi dan berita, apalagi dengan adanya sarana internet. Melalui media massa, pariwisata, kerja sama dalam

\footnotetext{
22 "Farewell Ceremony held by Ministry of Education and Culture, Indonesia for First Batch of Full-time Chinese Teachers of Indonesia who will leave for Studies in China" diunduh dari www.chinese.cn/hanban en/article/2012-07/25/content 450449.htm tanggal 13 Agustus 2012
}

23 "A 'Sinomania' for Indonesian Student" diunduh dari www.study-in-china.org/HostSchools/ CampusNews/201281713201310623.htm tanggal 21 Agustus 2012.

24 "Mahasiswa Indonesia di China 10.957 orang" Antara News. 14 April 2012.

25 I.Wibowo. ed. Retrospeksi dan Rekontekstualisasi Masalah Cina. (Jakarta: PT. Gramedia Pustaka Utama, 1999) 
pendidikan, dan melalui diplomasi publik kedua negara, rakyat Cina dan Indonesia dapat lebih akrab kenal.

Dalam konstelasi dunia abad ke-21, dimana peran Cina dan Indonesia di panggung dunia akan lebih menentukan, perguruan-perguruan tinggi kita harus lebih antisipatif dan naik ke level lebih tinggi, mencetak lebih banyak sinolog yang handal. Pengertian kita mengenai sinologi tidak lagi bisa dalam pengertian sempit, terfokus pada bahasa dan budaya Cina. Sinolog yang diperlukan adalah yang memahami sinologi sebagai contemporary China studies. Program Studi Cina FIB-UI adalah pelopor sinologi di Indonesia dan tetap merupakan rujukan bagi universitas lain yang menawarkan program studi serupa,akan tetapi mengingat bahwa misinya adalah pengembangan ilmu budaya dan bahasa Cina, maka mata kuliah yang ditawarkan adalah seputar sejarah, linguistik, kesusastraan dan bahasa Cina. Orientasinya masih cenderung pada pengertian sinologi yang tradisional dan klasik, melihat ke belakang dan tidak ke depan.

Sudah waktunya kita berfikir lebih jauh untuk mendidik sinolog yang menguasai displin ilmu politik, ekonomi, sosial dan budaya masyarakat Cina kontemporer, ditunjang oleh kemahiran bahasa Mandarin. Dr Gondomono, bersama dengan Myra Siddharta dan almarhum Ong Hok Ham, sudah lama menyadari hal ini dan pada tahun 1999 mendukung gagasan sekelompok alumni Jurusan Sinologi, Fakultas Sastra Universitas Indonesia, untuk mendirikan Center for Chinese Studies (CCS) di bawah payung Yayasan Pusat Studi Cina. CCS dipimpin oleh sinolog sejati Dr. I Wibowo (alm.), pakar ilmu politik yang meraih gelar Doktor dari School of Oriental \& African Studies, London University, yang sekaligus menguasai bahasa Mandarin. ${ }^{26}$ Pendirian pusatpusat kajian serupa yang sifatnya multi-disiplin, terbuka terhadap semua ilmu, dan berorientasi pada kajian Cina modern perlu didukung oleh pemerintah dan kalangan swasta. Pusat-pusat kajian tersebut juga diperlukan untuk menampung mahasiswa Indonesia yang sekarang kuliah di luar negeri dalam berbagai disiplin ilmu, tidak saja di RRC, serta menguasai bahasa Mandarin, agar mereka memiliki wadah untuk bisa mengembangkan dan mengamalkan pengetahuan mereka.

Kita dapat bercermin pada perkembangan sinologi di Eropa dimana sampai pada tahun 1960-an sinologi masih didominasi oleh ilmu-ilmu klasik. Alhasil mereka yang ingin memahami perkembangan terkini RRC pada waktu itu terpaksa mengandalkan analisa para jurnalis, diplomat dan pakar ilmu sosial yang tidak menguasai bahasa Mandarin dan tidak dapat menggunakan sumber-sumber primer dalam analisa mereka. Perubahan baru terjadi pada pertengahan tahun 1980-an saat pusat-pusat sinologi utama di Eropa mulai membuka diri terhadap kajian Cina kontemporer. Sekarang mulai muncul beberapa di antara generasi ke-tiga pakar Cina di Eropa yang mahir dalam

\footnotetext{
${ }^{26}$ Dr I Wibowo wafat pada bulan November 2010 dan untuk sementara CCS sedang non-aktif. Koleksi luas buku Cina kontemporer CCS sekarang tersimpan dalam koleksi khusus perpustakaan STF Driyarkara.
} 
bahasa Mandarin dan sekaligus kuat dalam suatu ilmu disiplin sosial lain, seperti Heike Holbig, Maria Heimar, Flora Sapio, dan Sebastian Heilmann. ${ }^{27}$

Normalisasi hubungan diplomatik dengan RRC sudah berlangsung sejak tahun 1990, 22 tahun yang lalu. Presiden Abdurrahman Wahid mencabut Inpres No.14/1967 sudah 12 tahun silam. Peluang untuk belajar bahasa Mandarin sudah terbuka luas, melalui pendidikan non-formal ataupun formal, di dalam negeri maupun di Cina sendiri. Oleh karenanya sudah saatnya kita berfikir mengenai tahap berikut pengembangan studi Cina.

Seperti yang telah disampaikan oleh seorang diplomat Inggris kepada penulis, "It is hard to believe that in a country as important as Indonesia, with its ambitions in the region and China right at its front door, there are so few China experts." Memang demikianlah kenyataannya sekarang. Oleh karena itu, kita harus segera mempersiapkan lebih banyak sinolog yang tidak saja mahir berbahasa Mandarin tetapi juga menguasai ilmu politik, ekonomi, sosial, dan budaya agar Indonesia mampu secara cerdas dan antisipatif menghadapi suatu masa depan dengan Cina sebagai kekuatan besar dunia, persis di halaman depan kita.

\section{DAFTAR PUSTAKA}

Cheng Li (ed.). China's Emerging Middle Class: Beyond Economic Transformation. Washington DC: Brookings Institution Press. 2010.

Economy, Elizabeth. "Time for a Strategic Reset”. America's Quarterly Winter. 2012.

Goh, Evelyn. 2011. "Rising Power...to do what?: Evaluating China's Power in Southeast Asia". RSIS Working Paper no. 226.

Gondomono. "The Development of the Teaching of Chinese Language in Indonesia", Jurnal Ilmiah Darma Persada Tahun III/3/Juli 2005. 2005.

Hidayat, Komaruddin dan Putut Widjanarko (ed.). Reinventing Indonesia: Menemukan Kembali Masa Depan Bangsa. Jakarta: Mizan. 2008.

Hong Liu. China and the Shaping of Indonesia 1949-1965. Kyoto CSEAS Series on Asian Studies 4. Kyoto: Center for S.E. Asian Studies Kyoto University. 2011.

Wibowo, I. (ed). Retrospeksi dan Rekontekstualisasi Masalah Cina. Jakarta: PT. Gramedia Pustaka Utama. 1999.

Wibowo, I dan Syamsul Hadi (ed.). Merangkul Cina: Hubungan Indonesia-Cina PascaSoeharto. Jakarta: Gramedia Pustaka Utama. 2009.

Wibowo, I dan Thung Ju Lan (ed.). Setelah Air Mata Kering: Masyarakat Tionghoa PascaPeristiwa Mei 1998. Jakarta: Penerbit Buku Kompas. 2010.

Lohanda, Mona. Growing Pains: The Chinese and the Dutch in Colonial Java, 1890-1942. Jakarta: Yayasan Cipta Loka. 2002.

\footnotetext{
${ }^{27}$ Bjordgaard. Op.cit.
} 
Liang, Liji. Dari Relasi Upeti ke Mitra Strategis: 2000 Tahun Perjalanan Hubungan Tiongkok-Indonesia. Jakarta: Penerbit Buku Kompas. 2012.

Luhby, Tami. “China's growing middle class”. CNN Money. 26 April 2012. 2012.

Rapoza, Kenneth. "Within a generation, China middle class four times larger than America's" Forbes. 2011.

Reid, Anthony (ed.). Indonesia Rising: The Repositioning of Asia's Third Giant. Singapore: ISEAS. 2012.

Shambaugh, Sandschneider dan Zhou (ed.) China-Europe Relations: Perceptions, policies and prospects. New York: Routledge. 2008.

Sukma, Rizal. "Indonesia's Response to the Rise of China: Growing Comfort amid Uncertainties" dalam _Rise of China: Responses from Southeast Asia and Japan. NIDS Joint Research Series no.4, 2009. 2009.

. "After regaining unity, it is time to move forward." The Jakarta Post. 2012.

Storey, Ian. "Progress and Remaining Obstacles in Sino-Indonesian Relations." China Brief Vol.5 No.18. Jamestown Foundation.

Suryadinata, Leo. Eminent Indonesian Chinese: Biographical Sketches. Singapore: Gunung Agung. 1981.

UNDP, Human Development Report 2011.

Wanandi, Jusuf. Shades of Grey: A political memoir of Modern Indonesia 1965-1998. Jakarta: Equinox. 2012.

World Bank. From poor areas to poor people: China's evolving povery reduction agenda. Washington DC: World Bank, March 2009.

Wu Chongbo. "Forging Closer Sino-Indonesian Economic Relations and Policy Suggestions." Ritsumeikan International Affairs Vol. 10 2011. 2011. 